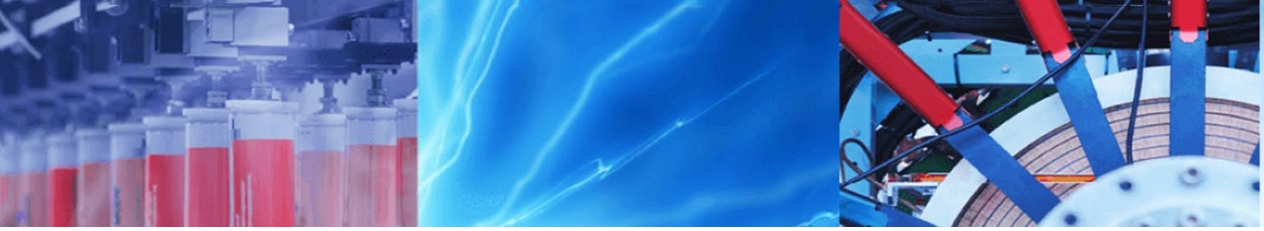

Research Article

\title{
Synthesis and abrasive wear performance of stir cast AA6063-TiC composite materials
}

\author{
S. Saravanan ${ }^{1} \cdot$ M. Ravichandran ${ }^{2} \cdot$ A. V. Balan ${ }^{3} \cdot$ P. Senthilkumar ${ }^{3}$
}

Received: 31 May 2019 / Accepted: 5 November 2019 / Published online: 9 November 2019

(c) Springer Nature Switzerland AG 2019

\begin{abstract}
Typically Aluminum 6063 matrix composites have an extensive wear resistance application due to its high specific strength. Here the stir casting fabricated composites having 0, 3, 6 and $9 \mathrm{wt} \%$ of titanium carbide (TiC) are tested using a pin on disc sliding wear test equipment. Loads (P), speed (sliding and rotation) and sliding distance (D) are the input parameters. The improvement in hardness was observed when $\mathrm{TiC}$ content increases due to the homogeneous dispersion strengthening mechanism. The incorporation of TiC in the AA6063 matrix reduces the rate of wear (WR) and increases the resistance to wear. The "COF" reduces when the TiC composition increases. The "WR" and COF increase when ' $D$ ' and ' $P$ ' increases for all the compositions tested.
\end{abstract}

Keywords AA6063 · TiC ."WR" · Coefficient friction

\section{Introduction}

Aluminum alloy is the best alternative material for mechanical, structural and electrical parts because of its special properties. The major drawback of these alloys is low wear resistance particularly in sliding applications $[1,2]$. To overcome these problems composite materials are introduced for many applications including automotive and electronics industries [3, 4]. AA6063 is widely used in wear applications like cylinder liners, brakes, pistons, and motor casing. By improving the wear resistance of AA6063 and used in many more applications. The properties of the AA6063 changed by reinforcing with ceramic particles have been received superior properties. TiC pays attention due to its high hardness, strength, poor heat conduction, reduced tendency of particle agglomeration, thermodynamically stable with molten aluminum and good wetting compatibility [5-9]. Several investigations are focusing on the wear properties of the composites. According to Sannino and Rack, the significant process parameters can control the "WR" and "COF" in the Aluminum Matrix Composites (AMC) under dry sliding atmosphere $[10,11]$. Acilar and Gul investigated the effect of adding $\mathrm{SiC}$ in the aluminum matrix and found that "WR" increases when " $D$ " and ' $P$ ' increase [12]. Al-Qutub et al. observed that the addition of $10 \mathrm{vol} \% \mathrm{Al}_{2} \mathrm{O}_{3}$ particles improved the resistance to wear of AA6160 when related to the unreinforced alloy. The addition of $\mathrm{Al}_{2} \mathrm{O}_{3}$ content further improves the wear property by up to $145 \%$ [13]. The dry sliding behavior of $\mathrm{Al}-12 \mathrm{Si}_{4} \mathrm{Mg}$ alloy having cerium content found that increasing cerium until $2 \mathrm{wt} \%$ improves both resistance to wear and microhardness [14]. Canaki et al. [15] found that the larger size of $\mathrm{B}_{4} \mathrm{C}$ has more wear resistance than

S. Saravanan, nanosaran007@gmail.com | 'Department of Mechanical Engineering, K. Ramakrishnan College of Technology, Trichy 621112, India. ${ }^{2}$ Department of Mechanical Engineering, K. Ramakrishnan College of Engineering, Trichy 621112 , India. ${ }^{3}$ Department of Mechanical Engineering, K.S.R. College of Engineering, Tiruchengode 637215, India. 
the smaller size. Sahin [16] used ANOVA for analyzing the wear properties of AA2014-15 wt\% SiC composite. Koksal et al. [17] found that dry sliding wear property of $\mathrm{Al} / \mathrm{AlB}_{2}$ composites are influenced by normal " $\mathrm{P}$ ", reinforcement ratio, sliding velocity and distance using $L 9$ Taguchi orthogonal array. However, only a few studies are focused on TiC reinforced aluminum composites. The motive of this present research is to report the wear
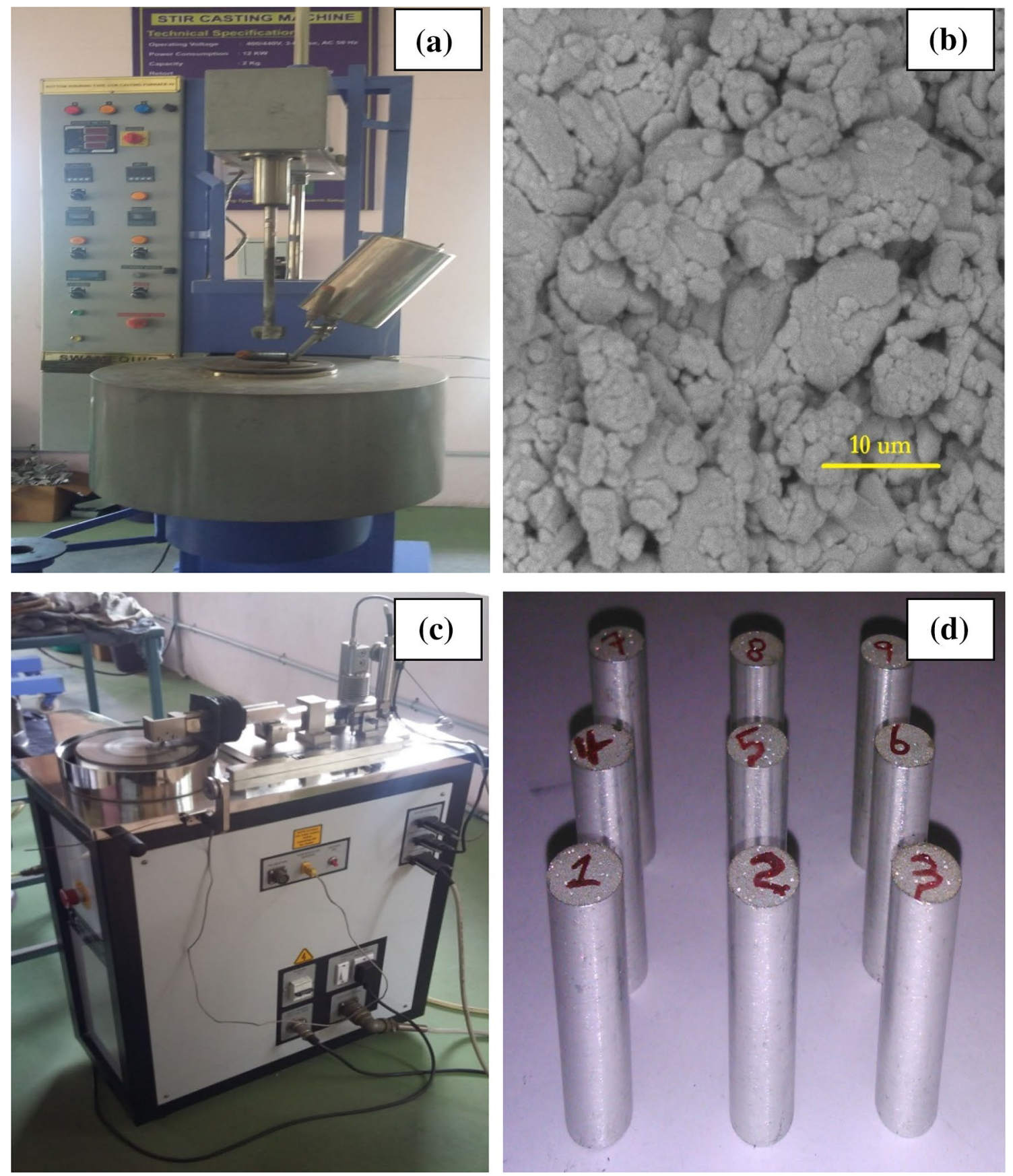

performance of AA6063-TiC composites using a pin-ondisc apparatus.

\section{Experimental details}

The matrix for this work is AA6063, having a density of $2.70 \mathrm{~g} / \mathrm{cm}^{3}$, elasticity modulus of $70 \mathrm{GPa}$ and good weldability. TiC particles were used as reinforcement. It has a 

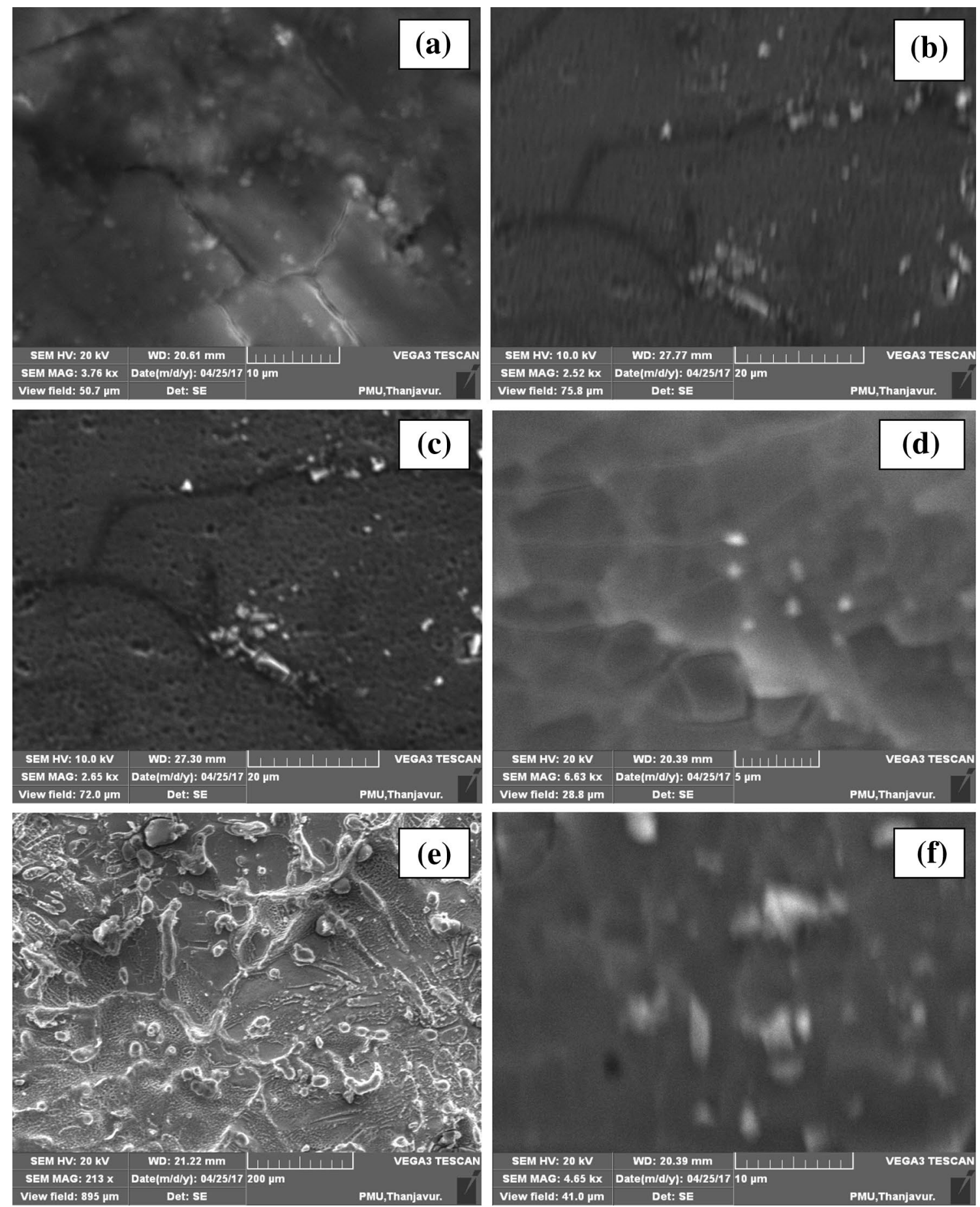

Fig. 2 SEM images of AA6063-TiC composites

density of $4.90 \mathrm{~g} / \mathrm{cm}^{3}$, modulus of elasticity $439 \mathrm{GPa}$ and good wettability. The composite was manufactured by using a stir casting route (Fig. 1a). The desired amount of matrix and reinforcement particles were taken and the morphology shown in Fig. 1b. The weight percentage of TiC particles used for dispersion was $3 \%, 6 \%$ and $9 \%$ with AA6063. AA6063 was melted to furnace at $750{ }^{\circ} \mathrm{C}$ and stirred with DC motor controlled stirrer. The TiC contents were dispersed in the matrix at $730^{\circ} \mathrm{C}$. The molten AA6063 with reinforced TiC particles were poured into cast iron mold and allowed to solidify. According to ASTM E92, at room temperature, Vickers indenter with $0.5 \mathrm{~kg}$ load and dwell time of $30 \mathrm{~s}$, the test was conducted in microhardness tester. The measurements are made in 

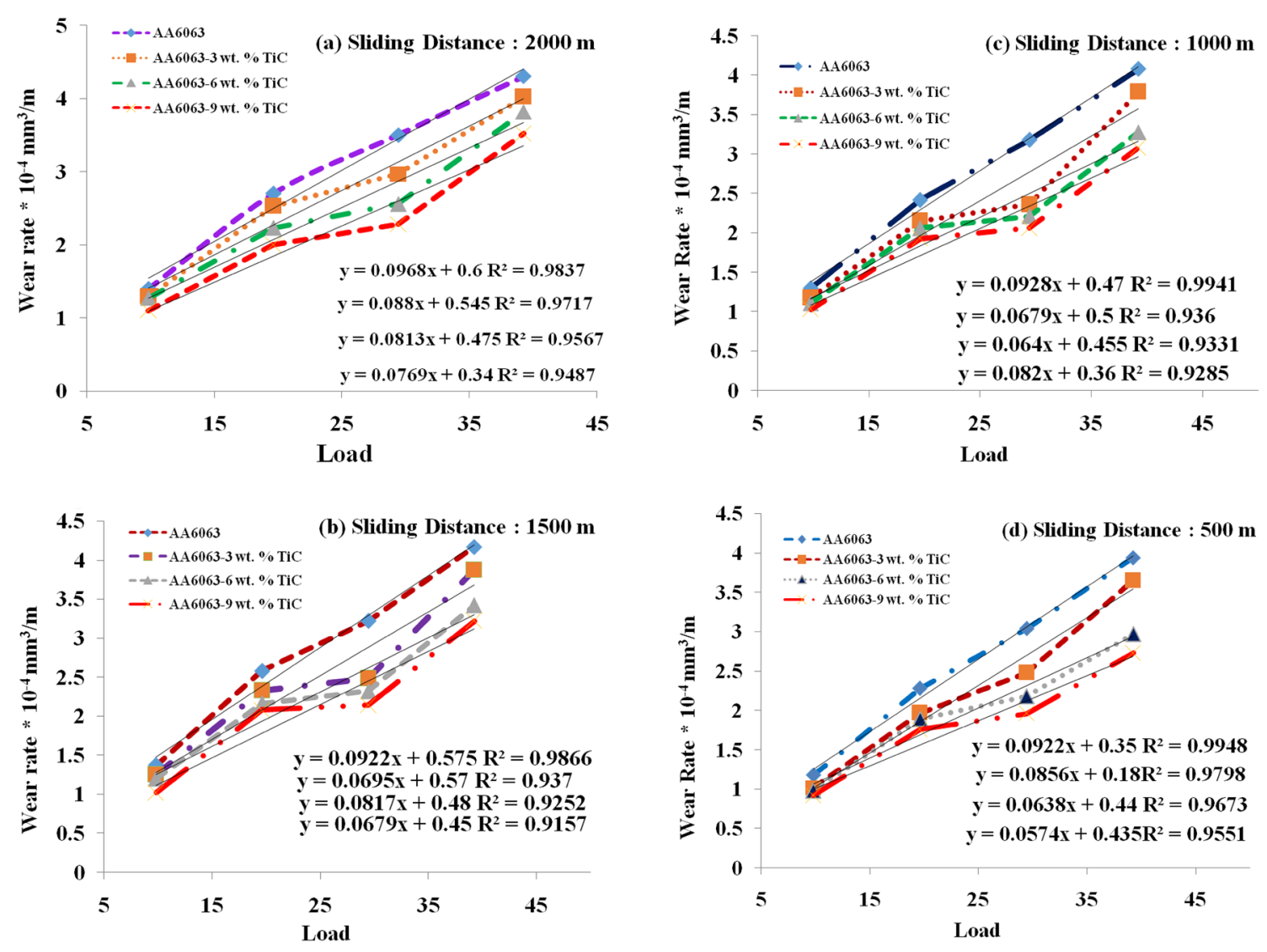

Fig. 3 Effect of "WR" on "D" a 2000 m, b 1500 m, c 1000 m d 500 m of AA6063-TiC composites

different locations and the mean readings are taken as their hardness.

Pin on disc apparatus is used to test the abrasive wear (Fig. 1c) as per the standards ASTM G99, The samples were a cylindrical shape of size $30 \times 10 \mathrm{~mm}$ is shown in Fig. $1 \mathrm{~d}$. Before testing, the flat surface was polished. During testing, the specimen was forced on the EN 31 steel horizontal rotating disc having 600 grit $\mathrm{SiC}$ abrasive paper. The tests were accomplished with "P"s $10 \mathrm{~N}, 20 \mathrm{~N}, 30 \mathrm{~N}$ and $40 \mathrm{~N}$, $\mathrm{TiC}$ weight percentages $0 \mathrm{wt} \%, 3 \mathrm{wt} \%, 6 \mathrm{wt} \%$ and $9 \mathrm{wt} \%$, sliding velocities $1 \mathrm{~m} / \mathrm{s}, 2 \mathrm{~m} / \mathrm{s}, 3 \mathrm{~m} / \mathrm{s}$ and $4 \mathrm{~m} / \mathrm{s}$ and "D"s $500 \mathrm{~m}, 1000 \mathrm{~m}, 1500 \mathrm{~m}$ and $2000 \mathrm{~m}$.

Initially, the digital balance having an accuracy of $0.001 \mathrm{mg}$ was used to measure the mass of the specimens. Specimens have been washed by acetone, their weight was noted again. The change of mass loss before and after the test was observed. Yigezu et al. [9] Eq. (1) is used to compute the "COF". The tests were repeated thrice and their average was taken.

"COF" $\mu=\frac{\text { Tangential force }}{\text { Normal force }}$

\section{Results and discussion}

\subsection{Microstructural effect}

The rigidity of the AA6063 composite has increased by adding $\mathrm{TiC}$ reinforcements as that of Kaftelen et al. [18] findings. The images are shown in Fig. 2a-f are SEM pictures of AA6063-TiC composites produced by stir casting route. The results of the microstructural analysis showed that the TiC distribution in the composite is in the expected uniform level. This is purely because of the selection of the fabrication method of composites. Figure $2 \mathrm{f}$ proved that interfacial bonding between Aluminum and $9 \mathrm{wt} \%$ of TiC particles are found to be superior. The agglomeration is as expected for the composites contain more weight percentage of reinforcement but here the stirring action during the casting process facilitates to produce agglomeration free composites.

\subsection{Wear effect}

Figure 3a-d shows that "WR" depends on "P" applied and " $D$ ". When increasing the " $P$ ", wear increases due to 

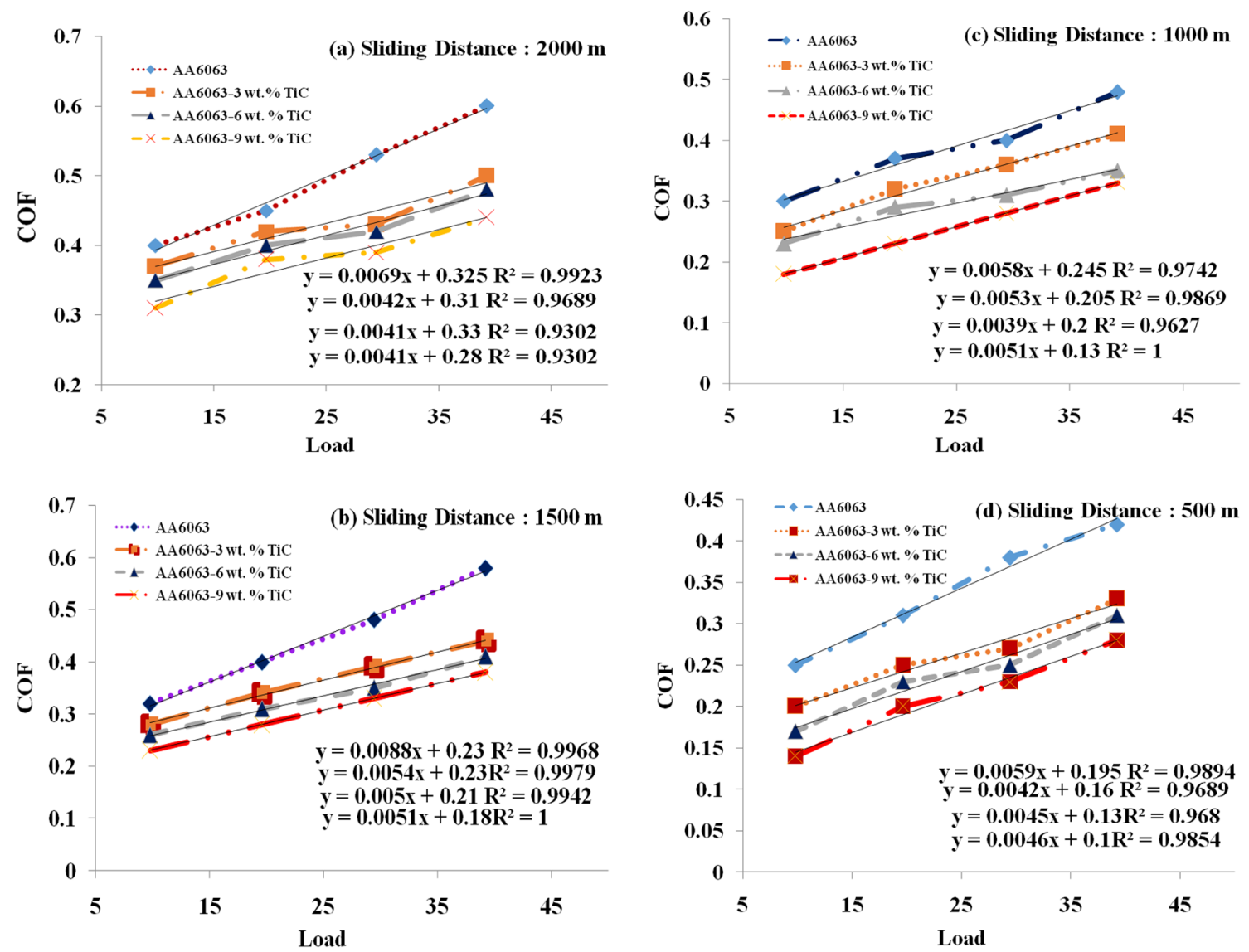

Fig. 4 Effect of "COF" on "D" a 2000 m, b 1500 m, c 1000 m d 500 m of AA6063-TiC composites

the friction created among the sample and counterface. Also, "WR" reduces because of a rise in the hardness of the AA6063-TiC composites by the addition of secondary particle TiC. The wear mechanism observed for the TiC reinforced composite is abrasive wear. The inclusion of ceramic reinforcement in the aluminum alloy matrix converts the adhesive nature of wear into abrasive wear. The ceramic particles prevent the wear and resist the deformation during sliding of a pin on the surface of the composite. Figure 3a-d shows that TiC content affects the wear performance of the composite. Initially, the "WR" was increasing linearly against " $D$ ", " $P$ " and then it increases exponentially due to the nature of self-lubrication at the contact surfaces and relative variation of densities of proposed composites. It was perceived that the pure AA6063 experiences larger "WR" than the TiC reinforced composites. This phenomenon is due to the rise in " $\mathrm{P}$ " and metal to metal contact causes the insufficient formation of the carbon-rich layer in the contact areas which tend to break up the rigid asperities of the composite. The increase in "WR" is observed for all the samples irrespective of the composition for all the increasing " $P$ "s. Even though $\mathrm{TiC}$ resists the wear of the composite, an increase in " $P$ " increases the "WR" for the respective " $\mathrm{P}$ "s.

Figure 4a- $d$, shows that when " $\mathrm{P}$ " increases the "COF" also increases and a similar tendency was observed for all the composites. Further, the "COF" is far upper due to variation in the contact of the specimen. Less "COF" was attained for AA6063-9 wt\% TiC composites due to the presence of extra hard particles in the surface of the composite. Also, the increase in " $\mathrm{P}$ " is directionally proportional to the "WR" which is evident from the plotted graph, the $\mathrm{COF}$ also increases linearly. These results once again convince the findings. These findings are well supported by the previous researchers who reported for the wear studies of the AMCs.

The TiC reinforced composites demonstrate low "COF" when related to the pure AA6063 matrix. Furthermore, the heat produced in the contact surfaces during the relative motion enhances the "COF" due to the existence of the carbon-rich layer and heat dissipation does not take place. Accordingly, the rigid severities of the composites, the "COF" for the TiC integrated AMC decreases when compared to pure AA6063. These features assist in controlling 

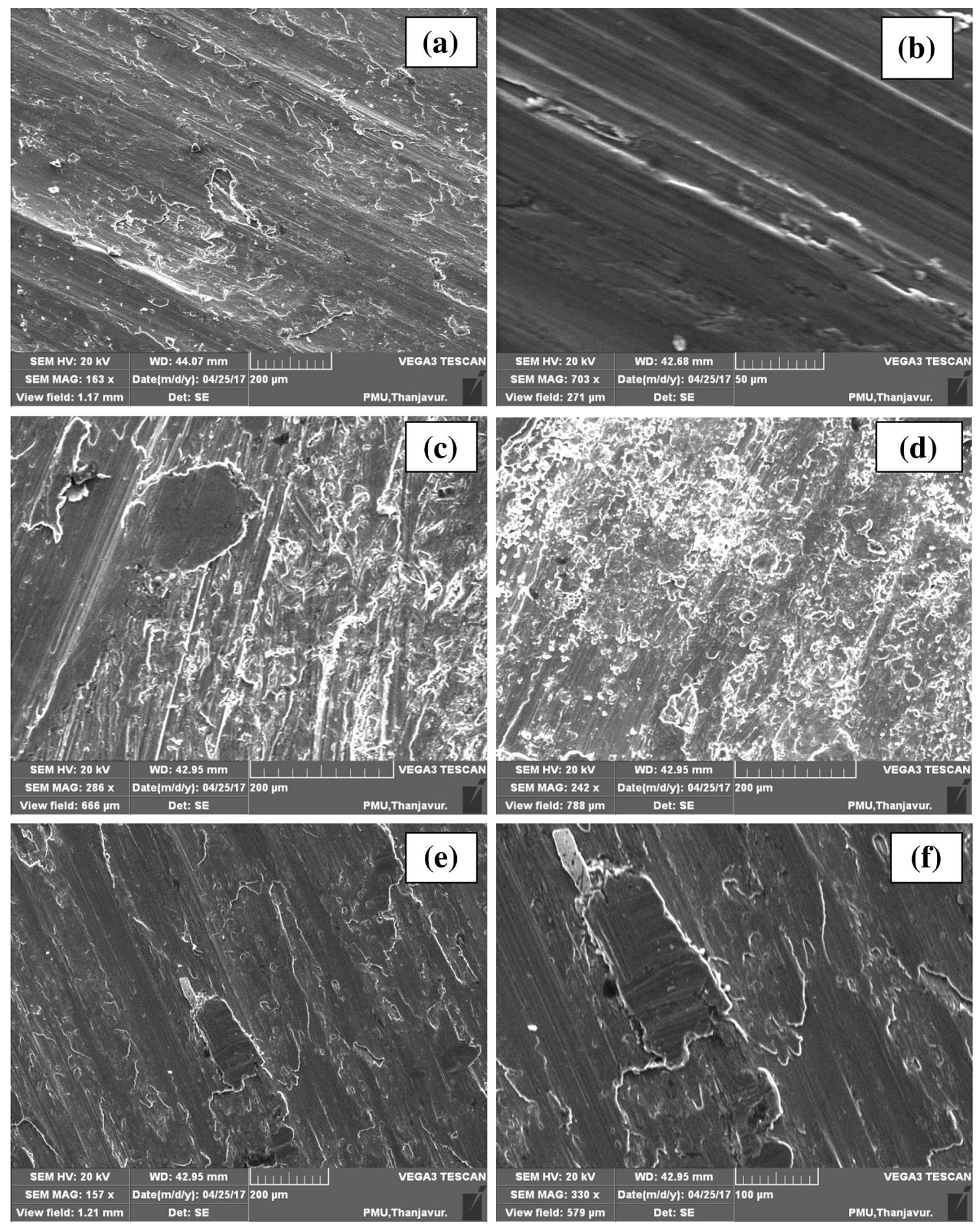

Fig. 5 Effect of "WR" on “D” a 2000 m, b 1500 m, c 1000 m d 500 m of AA6063-TiC composites

the "COF" in AA6063-TiC composites. For all the AA6063$\mathrm{TiC}$ composites samples, the "COF" raises with a rise in the "P" and "D".

During the initial phase of wear, an oxide film formed on the surface of AA6063-TiC composite might greater wear resistance. The wear resistance of the composites improved, due to the form that, at the initial stage, the contact surface normally consists of valley and hills. But for the higher value of sliding distance, these surfaces are getting finer and influencing the wear resistance of the composites [19]. The hard TiC on the surface producing layer and when the distance and speed increase, irrespective of load the wear resistance improved. The increase in weight percentage of $\mathrm{TiC}$ declines the wear

\section{SN Applied Sciences}


of the composite and $\mathrm{TiC}$ resists the wear because the hardness of the TiC is higher than the counterpart and matrix material of the composite. The TiC sliding over the surface and change the nature of along with the carbide layer over the surface [20].

The micrographs are shown in Fig. $5 a-f$ are worn surfaces of AA6063-TiC composites fabricated through stir casting method. This SEM microstructural analysis was done to explore the characteristics of the worn-out surfaces of the newly fabricated composite materials. The results illustrated that the increase in " $D$ " increases the "WR" because of reinforcement pullouts as shown in Fig. 5a. The clear morphology of the wear track is shown in Fig. 5 a which shows how the pin is penetrated over the surface of the proposed composite. The severe plastic deformation is observed for the higher " $\mathrm{P}$ " and " $\mathrm{D}$ " as shown in Fig. $5 \mathrm{~b}$ and c. This is due to the high " $\mathrm{P}$ " and this "P" makes the harder pin travel deeply over the surface. The higher sliding velocity leads to the formation of wear debris as shown in Fig. 5d. Figure $5 e$ and $f$ show the worn surface of the composite has $9 \mathrm{wt} \%$ of TiC and the hard and wear-resisting nature of $\mathrm{TiC}$ are visible in these images.

\section{Conclusion}

Based on this investigation, the following conclusions were made.

- The hardness increases with increasing the wt \% of TiC due to uniform dispersion strengthening mechanism.

- The inclusion of TiC to AA6063 reduces the "WR" of the matrix and thereby increasing the wear resistance due to self-lubricating properties.

- The "COF" reduces with the inclusion of TiC particles due to the presence of intermetallic phases.

\section{Compliance with ethical standards}

Conflict of interest The authors declare that there are no conflict of interest.

\section{References}

1. Li P, Kandalova EG, Nikitin VI (2005) In situ syntheses of Al-TiC in the aluminum melt. Mater Lett 59:2545-2548

2. Wang J, Song K, Tong C, Tian G, Wu J, Gao H, Xu J (2017) $\mathrm{TiO}_{2}-\mathrm{B} / \mathrm{Ag}$ Nanocomposite wires enhanced electrochemical performance for Li-ion batteries. J New Mater Electrochem Syst 20(4):183-188

3. Zhaohui H, Xiaohua Y, Peixian Z, Shenggang Z, Yi Y (2017) Formation mechanism of phase interface for diffusion couple of $\mathrm{Pb} / \mathrm{Sn}$ layered composite. J New Mater Electrochem Syst 20(2):83-87

4. Saravanan $S$, Senthilkumar $P$, Ravichandran $M$, Anandakrishnan $\checkmark$ (2017) Mechanical, electrical and corrosion behavior of AA6063/TiC composites synthesized via stir casting route. J Mater Res 32(3):606-614

5. Contreras A, Albiter A, Perez R (2004) Microstructural properties of the $\mathrm{Al}-\mathrm{Mg} / \mathrm{TiC}$ composites obtained by infiltration techniques. J Phys Condens Matter 16(22):2241-2249

6. Tyagi R (2005) Synthesis and tribological characterization of in situ cast Al-TiC composites. Wear 259:569-576

7. Mavros H, Karantzalis AE, Lekatou A (2012) Solidification observations and sliding wear behavior of cast TiC particulate reinforced $\mathrm{Al}-\mathrm{Mg}$-Si matrix composites. J Compos Mater 47(17):2149-2162

8. Navaneetha Krishnan G, Selvam G, Julyes SJ (2015) Development and mechanical studies of glass/banana fiber hybrid silica nanoparticles with epoxy bio-nano composites. J Chem Pharm Sci 7:197-199

9. Yigezu BS, Mahapatra MM, Jha PK (2013) On modeling the abrasive wear characteristics of in situ $\mathrm{Al}-12 \% \mathrm{Si} / \mathrm{TiC}$ composites. Mater Des 50:277-284

10. Sannino AP, Rack HJ (1995) Dry sliding wear of discontinuously reinforced aluminum composites: review and discussion. Wear 189:1-19

11. Acilar M, Gul F (2004) Effect of the "P", "D" and oxidation on the dry sliding wear behavior of $\mathrm{Al} 10 \mathrm{Si} / \mathrm{SiC}_{\mathrm{p}}$ composites produced by vacuum infiltration technique. Mater Des 25:209

12. Al-Qutub AM, Allam IM, Qureshi TW (2006) Effect of submicron $\mathrm{Al}_{2} \mathrm{O}_{3}$ concentration on dry wear properties of 6061 aluminum based composite. J Mater Process Technol 172:327

13. Anasyida A, Daud AR, Ghazali MJ (2010) Dry sliding wear behavior of $\mathrm{Al}-12 \mathrm{Si}-4 \mathrm{Mg}$ alloy with cerium addition. Mater Des 31:365-374

14. Canakci A, Arslan F (2012) Abrasive wear behavior of $B_{4} C$ particle reinforced Al2024 MMCs. Int J Adv Manuf Technol 63(5):785-795

15. Sahin $\mathrm{Y}$ (2010) Abrasive wear behavior of $\mathrm{SiC} / 2014$ aluminum composite. Tribol Int 43:939-943

16. Koksal S, Ficici F, Kayikci R, Savas O (2012) Experimental optimization of dry sliding wear behavior of in situ $\mathrm{AlB}_{2} / \mathrm{Al}$ composite based on Taguchi's method. Mater Des 42:124-130

17. Kaviya K, Saravanan S, Ravichandran M, Senthilkumar P (2015) Microstructural analysis of AA6063-5 and 7.5 wt. \% TiC nanocomposites. J Chem Pharm Sci 11:39-42

18. Kaftelen H, Unlu N, Goller G, Lutfi Oveçoglu M, Henein H (2011) Comparative processing structure-property studies of $\mathrm{Al}-\mathrm{Cu}$ matrix composites reinforced with TiC particulates. Compos Part A 42:812-824

19. Baskaran $S$, Anandakrishnan V, Duraiselvam M (2014) Investigations on dry sliding wear behavior of in situ casted AA7075$\mathrm{TiC}$ metal matrix composites by using Taguchi technique. Mater Des 60:184-192

20. Zhu H, Jar C, Song J, Zhao J, Li J, Xie Z (2012) High temperature dry sliding friction and wear behavior of aluminum matrix composites $\left(\mathrm{Al}_{3} \mathrm{Zr}+\mathrm{a}-\mathrm{Al}_{2} \mathrm{O}_{3}\right) / \mathrm{Al}$. Tribol Int 48:78-86

Publisher's Note Springer Nature remains neutral with regard to jurisdictional claims in published maps and institutional affiliations. 